\title{
Proposta de adoção de sistema de milhagem por aplicativos de carona
}

\section{Proposal of adoption of loyalty programs by carpool applications}

\author{
Moisés Leite Santos Mestre em Propriedade Intelectual e Transferência de Tecnologia para a Inovação. Instituto Federal da \\ Bahia (IFBA) - Brasil. kaleul@gmail.com \\ Eduardo Oliveira Teles \\ Doutor em Engenharia Industrial. Instituto Federal da Bahia (IFBA) - Brasil. eduardo.teles@ifba.edu.br \\ Marcelo Santana Silva \\ Pós-Doutor em Engenharia Industrial e Doutor em Energia e Ambiente. Instituto Federal da Bahia (IFBA) \\ - Brasil.marcelosilva@ifba.edu.br \\ Marcio Luis Valença Araújo Doutorado em Modelagem Computacional e Tecnologia Industrial. Instituto Federal da Bahia (IFBA) - \\ Brasil.maraujo.valenca@gmail.com \\ André Luis Rocha de Souza Doutor em Engenharia Industrial. Instituto Federal da Bahia (IFBA) - Brasil. \\ andre_financas@yahoo.com.br \\ Fabio Marques da Cruz Doutor em Ciência da Informação. Instituto Federal da Bahia (IFBA) - Brasil. fabiomacz@gmail.com
}

\section{RESUMO}

A economia compartilhada é hoje uma realidade tangível. Esse tipo de economia introduziu a uma nova forma de consumo, em que as pessoas preferem alugar, tomar emprestado ou compartilhar, em vez de comprar. Com vistas a estudar este fenômeno cada vez mais presente no dia a dia, esta pesquisa analisa os principais aplicativos de compartilhamento de carona e propõe uma adequação tecnológica para implementação de sistema de milhagem visando a popularização e incentivo deste tipo de serviço. Trata-se de uma pesquisa de natureza tecnológica, exploratória com levantamento bibliográfico. Foram comparados três aplicativos de carona buscando verificar a possibilidade de adequação dos aplicativos escolhidos e realizadas simulações para validação da proposta. Foi possível verificar que o uso de sistemas de milhagem pode ser incluído como forma de pagamento nos aplicativos.

Palavras-chave: Economia compartilhada. Carsharing. Carpooling. Carona.

\section{ABSTRACT}

Shared economy is a tangible reality today. This type of economy has introduced a new form of consumption, one in which people prefer to rent, borrow or share rather than buy. With the intention of studying this increasingly present phenomenon, this research analyzes the main applications of carpool and proposes a technological adequacy for implementation of loyalty program aiming at the popularization and incentive of this type of service. It is a research of a technological nature, exploratory with a bibliographical survey. Three car sharing applications were compared seeking to verify the suitability of the chosen applications. For proposal validation purposes simulations were performed. It was possible to verify that the use of mileage systems can be included as a form of payment in the applications.

Keywords: Collaborative consumption. Car sharing. Carpooling. Car ride. 


\section{INTRODUÇÃO}

O espaço geográfico brasileiro tem enfrentado um dilema no que diz respeito à mobilidade urbana. $A$ quantidade de veículos circulando nas ruas de pequenas e grandes cidades vêm crescendo a cada dia. As regiões que concentram a maior parte dos serviços e atividades econômicas são as áreas que mais circulam os veículos individuais provocando um verdadeiro inchaço no trânsito (ROCHA, 2018).

A melhoria na qualidade e na oferta de opções de transporte público poderia levar à diminuição no uso de carro particular. Igualmente, os estímulos ao uso de bicicletas e ciclovias específicas poderiam levar à melhoria da qualidade do ar e contribuir com impactos positivos ao meio ambiente sendo, portanto, uma saída sustentável e visionária (SILVA et al., 2017).

Nesse contexto, destacam-se as caronas compartilhadas que, por sua vez, podem promover a redução de automóveis nas vias, o que pode gerar benefícios tanto para mobilidade urbana quanto para o meio ambiente, na medida em que contribui para a redução de emissão de poluentes. Nessa perspectiva, os aplicativos de carona compartilhada têm facilitado o uso dessa modalidade para que usuários (caroneiros e motoristas) se comuniquem e definam os detalhes do trajeto, bem como os valores (pecúnia) a serem pagos aos motoristas.

A proposta de adoção de sistemas de milhagem por aplicativos de carona ocorre em função da sua potencialidade como alternativa de pagamento, similar às oferecidas em companhias aéreas. Associar os sistemas de milhagem a esse nicho de mercado significa oportunizar aos usuários utilizarem suas milhas da forma mais conveniente possível. O fato de tal serviço estar disponível já constitui uma vantagem, pois cria uma alternativa de pagamento que beneficiará as pessoas que os utilizam ou não.

Em face do exposto, a presente pesquisa buscou responder ao seguinte questionamento: qual a viabilidade técnica e processual de implementação do sistema de milhagem em aplicativos de compartilhamento de carona? Assim, o objetivo geral foi analisar a viabilidade técnica e processual para ao sistema de milhagem em aplicativos de compartilhamento de carona. De forma específica, busca-se: a) investigar o funcionamento do sistema de milhagem; b) realizar a análise de diferentes ferramentas disponíveis aplicadas ao compartilhamento de carona em relação as suas funcionalidades, vantagens e limitações; e c) realizar simulações para validar a proposta de adequação tecnológica para implementação de sistema de milhagem.

Assim, a pesquisa traz contribuições práticas, pois a proposta gera um diferencial de mercado que poderá aumentar o interesse dos indivíduos em deixar seus veículos em casa e adotarem esse tipo de prática no tocante às contribuições tecnológicas, a pesquisa apresentada evidencia um potencial atrativo de associar os aplicativos de carona com o programa de milhagem.

\section{REVISÃO DE LITERATURA}

Esta seção apresenta as principais referências bibliográficas que serviram de base para o desenvolvimento dessa pesquisa aplicada. São abordados conceitos e a percepção de diversos autores sobre cada um dos temas de abrangência deste trabalho, a saber: sistemas de milhagem, carpooling, carsharing, mobilidade urbana e consumo colaborativo. A ordem dos temas segue a sequência de desenvolvimento da pesquisa.

\subsection{Mobilidade urbana e consumo colaborativo}

A mobilidade urbana é gerada a partir da circulação de bens, passageiros, habitação, transportes de cargas e infraestrutura viária (BARROS, 2018). Com o aumento do uso de novas tecnologias da informação e da comunicação, é de se esperar que o contexto da mobilidade urbana e seu estudo passem por mudanças intensas e seja incluso nesse processo. 
Autores como Machado e Piccinini (2018) argumentam que é indispensável a criação de mecanismos que busquem tornar os espaços públicos de trânsito nas cidades mais democráticos. Assim, há a necessidade imediata de projetos que busquem um trânsito educado, que estimulem o uso de transportes coletivos, que promovam um engajamento do setor empresarial e que gerem ações positivas.

Um projeto de mobilidade que poderá ser promissor é o que envolve o consumo colaborativo, pois está relacionado com a execução de atividades rotineiras que abarcam diferentes formas de compartilhamento (CHASE, 2015). Autores como Belk (2014) e Martin (2016) têm dado a devida atenção ao conceito de economia colaborativa, buscando uma base ontológica do conhecimento para esse fenômeno social. Os demarcadores de comportamentos sociais e técnicos têm sido mapeados, verificando-se que são oriundos do próprio ambiente, das relações sociais e tecnológicas. O estudo destes tem sido fundamental na especificação das vantagens e desvantagens relacionadas à adoção de um modelo de consumo colaborativo (SCHOR, 2017; FRENKEN, 2017).

O consumo colaborativo, segundo Zalega (2018), pode ser definido como um movimento social que ao mesmo tempo constitui-se em um novo modelo econômico que possibilita formas alternativas de atuação. Schor (2017) e Frenken (2017) associam o consumo colaborativo com outras atividades econômicas. Entretanto, os fatores que mais incentivam o desenvolvimento de práticas de consumo colaborativo, de acordo com Zalega (2018), são "fornecimento on-line de produtos, preocupações ambientais, ressurgimento da comunidade, tecnologias peer-to-peere consciência de custos".

Muitos projetos de mobilidade são voltados para veículo individual compartilhado. A oferta de serviços como o BlablaCar, Uber e outros são opções inteligentes de compartilhamento que suprem a necessidade das pessoas, além de impactar diretamente na economia, pois são mais viáveis a depender do estilo de vida e rotinas estabelecidas no seu dia a dia. Assim, existe um cenário positivo para o desenvolvimento do consumo colaborativo, uma vez que o crescimento da oferta de plataformas coletivas e a adesão a essas é uma evidência disso (CHASE, 2015; VARGAS, 2008).

\subsection{Carsharing}

O Carsharing é um compartilhamento de carros do tipo aluguel (feito por telefone ou internet), onde veículos podem ser retirados em várias estações ao longo de vias das cidades (com tempo de cerca de 1 minuto para disponibilidade) e utilizados por diferentes usuários ao longo do dia. Consiste em o usuário ter um único carro e possuir a liberdade de se locomover por locais variados, sem as responsabilidades inerentes a um proprietário, os custos e a manutenção que um veículo particular precisa (VTPI, 2018).

Segundo o Instituto de Políticas de Transporte \& Desenvolvimento - ITDP (2015), para viagens regionais, àquelas em que o uso de carro é prioritariamente solicitado, não é recomendado o uso do modelo carsharing, pois o carro passaria um longo período sem uso, ou seja, estacionado. Na configuração de aluguel, os veículos do tipo carsharing são usados para curtas distâncias no cenário urbano como uma medida alternativa de locomoção flexível, custo viável e que incentiva a sustentabilidade. O sistema pode trazer praticidade para usuários e contribuir para reduzir a frota de veículos nas ruas.

\subsection{Carpooling}

Furuhata et al. (2013) afirmam que o carpooling refere-se a um sistema de compartilhamento de transportes entre pessoas. O estudo do tema carpooling está presente em vários trabalhos desenvolvidos por diversos pesquisadores (BALDACCl; MANIEZZO; MINGOZZI, 2004; BRUCK et al., 2015). Constitui-se em transporte compartilhado, utilizado em contextos em que várias pessoas se deslocam de suas casas para um mesmo local, como o trabalho.

O projeto carpooling tem como objetivo montar grupos de carona com participantes com carro e/ou sem carro que possibilite, assim, um rodízio de carros dos grupos formados. O carpooling está fundamentado na partilha de um único veículo para a realização de um determinado trajeto por várias pessoas. O benefício 
direto está na redução dos custos para todos os usuários e na menor taxa de liberação de poluentes (BRUCK et al., 2015).

\subsection{Sistemas de Milhagem}

Os primeiros registros dos sistemas de milhagens são da década de 1950, mas ganharam força na década de 1980, quando empresas aéreas passaram a trocar certo número de milhas por passagens-prêmio (WANSINK, 2003). O programa AAdvantage foi o pioneiro sistema de milhagens criado pela empresa aérea norte-americana American Airlines em maio de 1981 (WINSHIP, 2011). As milhagens hoje possuem elementos de marketing de relacionamento, fidelização e satisfação plena do consumidor que não o levem a procurar outra empresa para a tomada de serviços.

Em 2017, as associações Expedia Affiliate Network e a Points Internationa/realizaram uma pesquisa para avaliar os sistemas de fidelidade nos cinco continentes e divulgaram os resultados no documento Trave/ Loyalty Report, em 2018. Os resultados demonstraram números positivos para os próximos anos no setor. O relatório aponta para os países que mais obtiveram crescimento no triênio de 2015-2017, posicionando a França em primeiro, com $94 \%$, o Brasil em terceiro, com $88 \%$ e o Japão em sexto com aumento de $70 \%$.

No Brasil, existem sistemas de fidelização em lojas de varejo (lojas de departamentos, supermercados, cosméticos etc.), postos de combustíveis e os mais clássicos cartões de créditos e companhias aéreas. As operadoras dos principais programas de fidelidade cresceram seu faturamento em 9,8\% no primeiro semestre de 2018 atingindo $R \$ 3,2$ bilhões entre janeiro e junho, segundo a Associação Brasileira de Empresas do Mercado de Fidelização (ABEMF, 2018).

Ainda segundo a $A B E M F$, o número de participantes desses programas chegou a totalizar 124,7 milhões em todo o país no fim do terceiro trimestre de 2018 , mostrando crescimento de $15,6 \%$ em relação ao mesmo período de 2017. E, com relação às emissões de milhas no mercado, a pesquisa também aponta um dado progressivo. No mesmo período, foram emitidos no Brasil 72,3 bilhões de pontos/milhas mostrando um crescimento de $16,4 \%$ em relação ao terceiro trimestre do ano anterior.

O crédito de milhas ou pontos varia de acordo à empresa prestadora do serviço, segmento delas, classificação do cliente e do produto. Desta forma, a integração dos serviços que permitem a transferência de pontos de outras origens como cartões de crédito e postos de combustíveis para milhas aéreas são uma forte tendência, permitindo acumular mais rapidamente premiações que são possibilitadas por meio da rede de fidelização (LIMA, 2015).

Assim, a lealdade do consumidor pode ser mantida através de uma rede de promoções e parceiros que também utilizam a milhagem como forma de pagamento. Apesar de não ser um método tão recente, 0 sistema de milhagem também pode ser entendido como uma espécie de moeda virtual prática que, além da praticidade de operação, estabelece um relacionamento frequente do usuário com as empresas que o utilizam.

\section{MATERIAIS E MÉTODOS}

Para alcançar os objetivos propostos na pesquisa, adotou-se uma metodologia de natureza tecnológica, que buscou gerar conhecimentos para uma possível aplicação prática, a qual se refere à adoção de um sistema de milhagem a ser empregado em aplicativos de carona.

Quanto à finalidade, esse estudo se caracteriza como exploratório e explicativo. É exploratório, pois realizou levantamento bibliográfico, investigação dos aplicativos de transportes existentes, dos sistemas de milhagem para fidelizações utilizadas por companhias aéreas, postos de combustível, operadoras de cartão de crédito, entre outros. É explicativo por que foi necessária uma síntese geral do assunto que possibilitasse uma reflexão pormenorizada do objeto de estudo (LAKATOS; MARCONI, 2003).

Quanto aos procedimentos, o trabalho apresentado teve como método a pesquisa bibliográfica para a construção do referencial teórico e análise através de estudo comparativo dos aplicativos de 
compartilhamento de caronas mais utilizados, a partir das seguintes métricas: número de downloads, pontuação dos usuários e quantidade de avaliações (GIL, 2008).

Quanto à abordagem, é considerada de caráter qualitativo, com análise de dados qualitativos e quantitativos. Qualitativo, pois investigou os aplicativos voltados à mobilidade urbana, em particular os de compartilhamento de carona/trajeto, e em que medida esses aplicativos são utilizados e sua eficácia. Também investigou o funcionamento do sistema de pontos/créditos utilizados por empresas que usam programas de fidelização por milhagem. Quantitativo, uma vez que realizou simulações com exemplos de deslocamentos e valoração do uso de milhagem.

O roteiro metodológico utilizado foi: (i) revisão da literatura incluindo artigos em revistas indexadas, periódicos, trabalhos acadêmicos, jornais e sites da internet; (ii) levantamento dos aplicativos de carona mais ranqueados na loja de aplicativos; (iii) listagem das características principais desses aplicativos; (iv) análise comparativa dos aplicativos e elaboração da proposta de adequação tecnológica através de fluxograma; (v) apresentação da simulação de quatro situações rotineiras de trajetos em pontos fixos urbanos e intermunicipais.

Para a escolha dos aplicativos, houve acesso à loja virtual dos dispositivos que utilizam o sistema Android, usando o termo de busca "carona". Uma grande variedade de aplicações foi retornada. A Tabela 1 lista as cinco mais utilizadas.

Tabela 1 - Ranking dos aplicativos de carona na loja Google Play

\begin{tabular}{llrcr}
\hline No & $\begin{array}{c}\text { Nome do } \\
\text { Aplicativo }\end{array}$ & $\begin{array}{r}\text { Quantidade } \\
\text { de instalações }\end{array}$ & Pontuação & $\begin{array}{c}\text { Quantidade de usuários } \\
\text { que pontuaram }\end{array}$ \\
\hline 01 & BlablaCar & $10.000 .000+$ & 4,4 & 991.001 \\
02 & WazeCarpool & $1.000 .000+$ & 3.8 & 10.227 \\
03 & Zumpy & $100.000+$ & 4.7 & 5.727 \\
04 & Garupa & $100.000+$ & 3.6 & 3.149 \\
05 & Carona Phone & $10.000+$ & 3.7 & 306 \\
\hline \multicolumn{4}{c}{ Fonte: Google (2019). }
\end{tabular}

Os sistemas selecionados para a análise foram o BlablaCar, Waze Carpool e Zumpy por serem os mais bem ranqueados. A finalidade é destacar os principais aspectos de cada um dos aplicativos e, então, justificar o porquê de a pesquisa propor o uso de sistemas de milhagem em aplicativos de carona.

Através das simulações, foi possível listar os valores de cada corrida, o total de cada trajeto no período e comparar utilizando sistema de milhagem. A partir desse resultado, será proposto a implementação de sistema de pagamento virtual bidirecional que dispensa o uso de dinheiro.

\section{ANÁLISE E DISCUSSÃO DOS RESULTADOS}

Nesta seção será apresentada uma análise comparativa de dados entre três dos aplicativos escolhidos com o intuito de verificar a possibilidade de adequação ao objetivo da pesquisa apresentado. Em seguida, apresenta-se a proposta de adequação tecnológica e os resultados de simulações de diferentes cenários obtidos a partir das médias dos aplicativos propostos.

O aplicativo BlablaCar foi criado na França por três estudantes em 2006, mas a ideia começou em 2003 quando planejaram uma forma de conectar motoristas a passageiros pela internet. Esse aplicativo tem como foco, geralmente, trajetos de média distância (BLABLACAR, 2019). O BlablaCar propicia a expansão da rede de relacionamento dos usuários através do estabelecimento de uma rede social que usa um índice pessoal de feedback como parâmetro para priorizar usuários com uma boa pontuação.

O aplicativo apresenta duas opções na tela inicial: oferecer carona e procurar carona. Cada uma das opções solicita o ponto de partida, destino, data e horário da saída. A publicação da oferta de carona possibilita 
o encontro de usuários que estão buscando aquele trajeto. O sistema apresenta interface com o usuário bem simples e amigável.

A empresa possui uma promoção para estimular os novos usuários a realizarem a sua primeira viagem. Essa promoção nasceu de uma parceria com o sistema de milhagem da rede de postos Ipiranga (Km de Vantagens) em que o usuário recebe o cupom promocional " 800 km de vantagens" após executar a primeira carona de $75 \mathrm{~km}$ ou mais. Os pontos ganhos no programa podem ser convertidos em abastecimento de combustível ou produtos de empresas parceiras como ingressos de cinema, entradas para museu e outros eventos (IPIRANGA, 2019).

O aplicativo Waze, criado em 2008 em Israel, é baseado na navegação por meio de satélite e colaboração dos usuários. Esse aplicativo é baseado em um mapa atualizado do local, associado a um preciso Global Positioning System (GPS) que possibilita a comunidade contribuir quase que em tempo real na atualização de informações como barreiras na pista, engarrafamentos ou qualquer outro fator que diminua a fluidez do trânsito.

Segundo a startup, o objetivo do aplicativo Waze ${ }^{1}$ é melhorar a mobilidade urbana por garantir os melhores ou mais econômicos trajetos e evitar os indesejados engarrafamentos. Para passageiros interessados em caronas disponibilizadas por motoristas usuários do aplicativo principal é necessária a instalação do aplicativo auxiliar Waze Carpool.

Após a instalação do aplicativo auxiliar, o Waze exibe a opção Carpool Driver, como adicional às funcionalidades de navegação existentes no aplicativo. O Capool Driver permite ao motorista agendar seus roteiros e horários para oferecer carona, porém essa função está disponível apenas no Brasil, nos Estados Unidos e em Israel. Já o módulo adicional Carpool Rider, é mais simples, pois é exclusivamente dedicado à busca de caronas.

O aplicativo Zumpy² foi criado no Brasil em 2017, e teve seu início em 2015 - em Belo Horizonte organizando grupo de caronas entre funcionários e estudantes de universidades. Este aplicativo permite selecionar os motoristas/passageiros por gênero, amigos das redes sociais ou grupos privados (colegas de trabalho, universidade). Outras vantagens do Zumpy são as parcerias com a rede de postos Ipiranga, DETRAN e diversas outras promoções.

O aplicativo apresenta opções similares em relação aos outros já mencionados, como a busca e a oferta de caronas. Entretanto, possui no menu principal a opção "Promoções" onde é possível visualizar ofertas especiais de produtos pela rede conveniada, também há a opção "Trocar meus créditos" a qual permite o pagamento de IPVA (Imposto Sobre a Propriedade de Veículos Automotores) ou a geração de cupom para abastecimentos.

O sistema de pagamento é eletrônico com cartão de crédito cadastrado, onde o aplicativo recebe o valor correspondente ao trajeto, retira a comissão de $10 \%$ e repassa o restante para o motorista em sua conta virtual.

\subsection{Análise comparativa}

A seguir, a análise dos aplicativos de carona (carpooling) que visam unicamente conectar os interessados a percorrer o mesmo trajeto compartilhando custos básicos da viagem. Nas pesquisas de literatura, web sites especializados e na própria loja virtual de aplicativos, foi possível encontrar informações peculiares dos três aplicativos escolhidos.

As informações obtidas de acordo com os critérios estabelecidos estão sistematizadas no Quadro 1. O critério definido para nortear a análise foram as limitações associadas ao uso do aplicativo.

\footnotetext{
${ }^{1}$ www.waze.com/pt-BR

${ }^{2}$ www.zumpy.com.br
} 
Quadro 1 - Aplicativos de carona mais utilizados

\begin{tabular}{|c|c|c|c|c|c|c|}
\hline No & $\begin{array}{l}\text { Nome do } \\
\text { Aplicativo }\end{array}$ & Origem & $\begin{array}{l}\text { Frequência } \\
\text { de uso }\end{array}$ & Vantagens & Limitações & $\begin{array}{c}\text { Referências de } \\
\text { pesquisa }\end{array}$ \\
\hline 01 & BlablaCar & França & Por demanda & $\begin{array}{l}\text { Rede social de } \\
\text { carona. } \\
\text { Quantidade de } \\
\text { usuários. } \\
\text { Estímulo para a } \\
\text { primeira viagem. }\end{array}$ & $\begin{array}{l}\text { Mais popular em } \\
\text { trajetos médios e } \\
\text { longos. }\end{array}$ & www.blablacar.com.br \\
\hline 02 & WazeCarpool & Israel & Por demanda & $\begin{array}{l}\text { Sistema de } \\
\text { geolocalização e } \\
\text { algoritmos } \\
\text { robustos. }\end{array}$ & $\begin{array}{l}\text { Necessário dois } \\
\text { aplicativos: Waze } \\
\text { para motoristas e o } \\
\text { WazeCarpool } \\
\text { somente para } \\
\text { passageiros. }\end{array}$ & www.waze.com/pt-BR \\
\hline 03 & Zumpy & Brasil & Por demanda & $\begin{array}{l}\text { Caronas urbanas } \\
\text { de trajeto curto. } \\
\text { Parceria com rede } \\
\text { de posto, DETRAN } \\
\text { e promoções. }\end{array}$ & $\begin{array}{l}\text { Pagamento } \\
\text { somente com } \\
\text { cartão. }\end{array}$ & www.zumpy.com.br \\
\hline
\end{tabular}

Fonte: Elaborado pelos autores (2019).

No Quadro 1 é possível verificar que cada um dos aplicativos analisados também possui características distintas quanto à origem e às vantagens, bem como limitações. Em relação às limitações, observa-se que cada aplicativo, individualmente, possui suas particularidades.

A limitação do BlablaCar foi a falta de difusão do aplicativo para uso em trajetos curtos, uma vez que o maior problema da mobilidade ocorre nos centros das grandes e médias cidades. Tal limitação faz com que o aplicativo seja mais utilizado em trajetos intermunicipais de média ou longa distância.

Com relação ao sistema Waze Carpool, verifica-se que é prático e de funcionamento mais leve, pois não traz os módulos de geolocalização, mas há necessidade de dois aplicativos: Waze para motoristas e o Waze Carpool somente para passageiros. Isso pode causar desestímulo nos usuários adeptos à carona. Usuários entusiastas da cultura da carona, geralmente, ofertam e são corriqueiramente passageiros. Por questão de comodidade, e até mesmo espaço disponível nos dispositivos, as duas funcionalidades poderiam ser adequadas para um só aplicativo.

Já a limitação encontrada no Zumpy está associada ao recebimento somente por cartão de crédito, ou seja, exclui os usuários não possuidores desse meio de pagamento. A assessoria da empresa explicou que para liberar o funcionamento legal do sistema não pode receber em dinheiro, pois isso caracterizaria "transporte clandestino". Ainda dentro desse contexto, outra limitação encontrada foi que os valores recebidos poderiam também ser utilizados para outra carona, uma vez que os créditos repassados pela empresa só podem ser utilizados para abastecimento, compra de alguns produtos promocionais da rede conveniada de postos e para pagamento de IPVA.

A partir da realização dessa análise comparativa, foi possível verificar que nenhum deles possibilita pagamento através de programa de fidelização. Desta forma, é possível avaliar a implementação do uso de sistemas de milhagem como forma de pagamento. Na próxima seção, será apresentada a proposta de adequação tecnológica, especificando os processos básicos de funcionamento geral de um sistema de carona com a inserção dos módulos de tratamento do sistema de milhagem. 


\subsection{Proposta de uso de sistema de milhagem nos aplicativos de carona}

Os sistemas de milhagem foram criados por empresas aéreas a fim de atrair o consumidor para uma fidelização de maneira que ele tenha algum tipo de vantagem no acúmulo da pontuação, seja para uso do mesmo serviço ou para compras de produtos diversos e externos aos oferecidos para empresa. $\mathrm{O}$ compartilhamento de veículos através de plataformas digitais aliadas a sistemas de milhagem corrobora estudos como os de Schor (2017) e Frenken (2017) que associaram uma diversidade de atividades econômicas ao novo modelo de consumo. Associar um conjunto de atividades, métodos e tecnologias existentes poderá potencializar a aderência à proposta. A integração pode ser compreendida, respectivamente, como: atividade rotineira de transporte, método de pagamento usando sistema de fidelização usando tecnologias on-line (LIMA, 2015).

A síntese da proposta de uso do sistema de milhagem nos aplicativos de carona é explicitada no Fluxograma 1 onde o processo padrão seria similar em todos os aplicativos, mas com destaque para as etapas onde ocorre o processamento das milhagens.

A partir da observação do fluxograma, pode-se verificar cada passo que o usuário (passageiro ou motorista) percorrerá no momento em que estiver utilizado o aplicativo:

O login é efetuado após a criação da conta (Item 1.1) onde são cadastrados os dados básicos do usuário. Os itens que são relacionados à milhagem estão no fluxograma na cor verde. A seguir, após o processo de cadastro, o usuário recebe na sua "conta corrente" um saldo inicial de utilização de 60 milhas (Item 1.2). A finalização do cadastro ocorre com as confirmações de segurança (Item 1.3).

Após o processo inicial de login no aplicativo, o usuário é levado à tela inicial onde são expostas as duas opções de uso: Oferecer Carona (Item 2) e Procurar Carona (Item 3), obedecendo aos seguintes passos: solicitação do local de partida (Item 2.1); informe do local de destino (Item 2.2); adição dos destinos adicionais que possibilitem outros trajetos menores (Item 2.3); especificação da data e horário da saída, respectivamente, de acordo o interesse (Itens 2.4 e 2.5); informe dos assentos disponíveis (Item 2.6).

Com base na distância do trajeto, o aplicativo informa ao ofertante da carona o valor estipulado a ser transferido (Item 2.7). Aceitando o valor, o sistema: divulgará o trajeto para os interessados, acompanhado de dados adicionais; realizará a reserva das milhas cobradas ao solicitante e concluirá a transferência somente após a execução da carona (Item 4.1). Como solicitante de um trajeto de carona (Item 3), o usuário seguirá passos similares: escolhe o local preferencial de saída (Item 3.1); seleciona o destino desejado (Item 3.2).

O fluxograma também descreve a data (Itens 3.3) e horário (Itens 3.4) desejado para buscar motoristas ofertantes, e quantos assentos serão necessários (Item 3.5). Após essas etapas, há uma busca pelos motoristas disponíveis e as informações sobre o mesmo (Itens 3.6 e 3.7). 
Fluxograma 1 - Proposta de adequação do sistema de milhas para aplicativos de carona

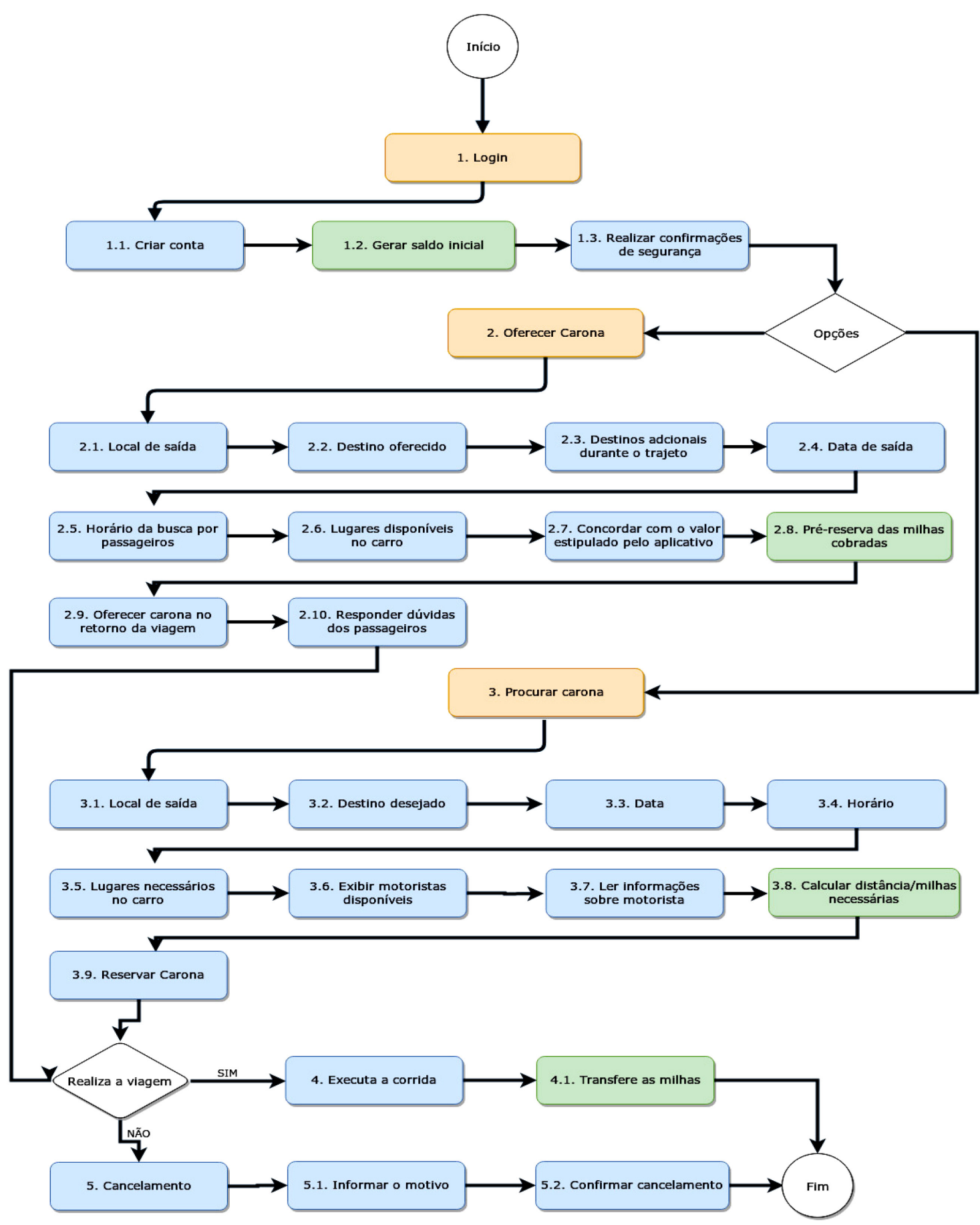

Fonte: Elaborado pelos autores (2019).

Após o interessado selecionar um motorista, o aplicativo expande a exibição do mesmo e informa dados mais detalhados para efetivação da viagem, incluindo o valor em milhas que foi estipulado pelo ofertante. A execução da corrida (Item 4) só é realizada quando confirmada pelo motorista e passageiro, então a quantidade definida em milhas é subtraída da conta do usuário-passageiro e é somada na conta corrente do usuário-motorista no fim da corrida. A etapa que o sistema transfere a contrapartida em milhas, acordada na reserva, é realizada internamente após a execução da carona (Item 4.1). 


\subsection{Simulações}

Para a realização desse estudo considerou-se que o consumo médio dos veículos compactos utilizando gasolina é de $12 \mathrm{~km} /$ /itro na cidade e de $14 \mathrm{~km} /$ litro na estrada (INMETRO, 2018). A média do preço do litro da gasolina medido entre 07 de janeiro a 15 de abril de 2019 foi de $R \$ 4,26^{3}$. No que se refere ao acúmulo de milhas, as principais operadoras de milhagem do Brasil (TudoAzul, Smiles, Amigo e Multiplus) utilizam diferentes critérios para cálculo do valor de cada milha.

O programa TudoAzul possui quatro (04) categorias: TudoAzul, Topázio, Safira e Diamante e para cada R\$ 1,00 gasto creditam 1, 3, 4 e 6 pontos, respectivamente (AZUL LINHAS AÉREAS, 2018). O programa Smiles possui quatro (04) categorias: Smiles, Prata, Ouro e Diamante que dão direito a percentuais de bônus por tarifa: $0 \%, 25 \%, 50 \%$ e $100 \%$ respectivamente, aplicados a classes de tarifa: Promocional, Light, Plus, e Max. Essas classes creditam para cada R\$1,00 gasto: 1, 1, 2 e 3 pontos, respectivamente (GOL, 2018).

O programa Amigo possui quatro (04) categorias: Bronze, Silver, Gold e Diamond que dão direito a percentuais de bônus por tarifa: $0 \%, 25 \%, 50 \%$ e 100\%, respectivamente, aplicados a classes de tarifa: Promo, Economy e Flex. Essas classes acumulam por compra 500, 1000 e 1500 para cada uma delas (AVIANCA, 2012).

O sistema Multiplus possui cinco (05) categorias: Latam, Gold, Platinum, Black e Black Signature e para obter a pontuação cada uma delas usa um multiplicador que é aplicado a cada dólar gasto na tarifa da passagem: 5, 6, 9, 10 e 11, respectivamente (LATAM, 2018).

Considerando que: (i) não há uniformidade na pontuação pelas empresas aéreas (variação de 1 a 6 milhas por um real gasto); (ii) há parceria entre as empresas Uber e operadora de milhagem Smiles que definiram a valoração dos pontos a cada real gasto, e (iii) para efetivação de parceria como esta, são realizados estudos de viabilidade de ambas as partes, as simulações apresentadas nesse trabalho seguem os mesmos parâmetros da parceria Uber/Smiles: acúmulo de três (3) pontos para cada $\mathrm{R} \$ 1,00$ gasto.

Quatro situações fictícias foram utilizadas para simular os trajetos na ida e na volta usando os aplicativos propostos. Em cada um dos cenários, foi obtida a média de custo de deslocamento utilizando os aplicativos analisados.

Na Simulação 1 foi definida a rota regular das cidades de Salvador-Feira de Santana (Estado da Bahia) tomando como parâmetro os valores sugeridos pelos aplicativos listados. A quilometragem média foi alinhada por todos os aplicativos nas simulações a seguir, utilizando os motores de localização que cada um integra. Por ser um trajeto intermunicipal, consideraram-se as Estações Rodoviárias de cada município como pontos de saída e chegada. Observou-se que a média do valor cobrado por $117 \mathrm{~km}$ percorrido nesse trajeto é de $\mathrm{R} \$ 23,30$ e, portanto, um Valor Médio por Quilômetro (V.M.K.) de R\$ 0,20.

$\mathrm{Na}$ Simulação 2 foi definida a rota regular da cidade de Lauro de Freitas partindo da Estação Rodoviária para a região central da cidade de Salvador, imediações da Avenida Sete de Setembro, no Bairro do Campo Grande. Observou-se que a média do valor cobrado por 31,9 km percorrido nesse trajeto é de R\$12,00 e, portanto, um Valor Médio por Quilômetro (V.M.K.) de R\$ 0,40.

Para a Simulação 3 foi definida a rota regular das cidades de Salvador-Camaçari (Estado da Bahia). Por ser um trajeto metropolitano, consideraram-se as Estações Rodoviárias de cada município como pontos de saída e chegada. Observou-se que a média do valor cobrado por $47 \mathrm{~km}$ percorrido nesse trajeto é de $R \$ 15,20$ obtendo, portanto, um Valor Médio por Quilômetro (V.M.K.) de R\$ 0,30.

E na Simulação 4 foi definida uma rota urbana dentro do município de Salvador, de um ponto do bairro Paripe, no subúrbio, até outro ponto no bairro Caminho das Árvores. Observou-se que a média do valor cobrado por 23,7 km percorrido nesse trajeto é de R\$ 10,50 obtendo, portanto, um Valor Médio por Quilômetro (V.M.K.) de R\$ 0,40.

Ao analisar os resultados obtidos referentes aos valores médios por quilometragem, observa-se uma diferença de preços variando de $\mathrm{R} \$ 0,20 / \mathrm{Km}$ até $\mathrm{R} \$ 0,40 / \mathrm{Km}$. Cumpre salientar que o consumo médio por trajetos feitos na estrada, ou seja, trajetos mais longos possibilitam que o veículo tenha um consumo menor

\footnotetext{
${ }^{3}$ Disponível em: https://pt.globalpetrolprices.com/Brazil/gasoline_prices/. Acesso em 16 de abr. de 2019.
} 
(INMETRO, 2019). Esse dado pode ser um dos fatores que contribuem para a diferenciação dos preços praticados baseados nas diferentes distâncias dos trajetos.

A Tabela 2 traz uma síntese das simulações, na sequência citada, definindo a quantidade de percursos semanais de cada cenário considerando a ida e volta, a quilometragem total, o valor gasto e a conversão para o sistema de milhagem com base na relação de 3 pontos/milhas para cada $\mathrm{R} \$ 1,00$. Além da periodicidade semanal, é possível observar também os custos anuais por passageiro. Para essa projeção, os valores semanais foram multiplicados pela quantidade de semanas existentes no ano, a saber, 52 semanas.

Tabela 2 - Custo por passageiro usando aplicativo de carona

\begin{tabular}{lcccccccc}
\hline $\begin{array}{c}\text { Trajeto por cenário } \\
\text { (Estado da Bahia) }\end{array}$ & $\begin{array}{c}\text { Percurso } \\
\mathbf{p} / \\
\text { semana }\end{array}$ & $\begin{array}{c}\text { Km } \\
\text { semanal }\end{array}$ & $\begin{array}{c}\text { Valor } \\
\text { semanal } \\
\text { (R\$) }\end{array}$ & $\begin{array}{c}\text { Acúmulo } \\
\text { milhas/ } \\
\text { semanal }\end{array}$ & $\begin{array}{c}\text { Percurso } \\
\text { p/ ano }\end{array}$ & $\begin{array}{c}\text { Km } \\
\text { anual }\end{array}$ & $\begin{array}{c}\text { Valor } \\
\text { anual } \\
\text { (R\$) }\end{array}$ & $\begin{array}{c}\text { Acúmulo } \\
\text { milhas/ } \\
\text { ano }\end{array}$ \\
\hline Salvador- Feira & 2 & 234,0 & 46,7 & 140 & 104 & 12.168 & $2.426,7$ & 7.280 \\
Lauro de Freitas - Ssa & 10 & 319,0 & 120,0 & 360 & 520 & 16.588 & $6.240,0$ & 18.720 \\
Salvador - Camaçari & 10 & 470,0 & 152,3 & 457 & 520 & 24.440 & $7.921,3$ & 23.764 \\
Paripe-C. das Árvores & 10 & 237,0 & 105,0 & 315 & 520 & 12.324 & $5.460,0$ & 16.380 \\
\hline
\end{tabular}

Fonte: Elaborado pelos autores (2019).

Em uma relação bidirecional, os valores tanto monetários como em milhagem são pagos ou transferidos da conta do passageiro para o motorista. Também em relação ao motorista, a quantidade máxima possível de valores ou milhas pagas por trajeto ainda podem ser múltiplas à quantidade de assentos disponíveis no veículo e, no que se refere ao passageiro, a relação é de 1 para 1.

Ao observar os resultados dos valores semanais e anuais, e comparando com os equivalentes em milhas, fica claro que utilizar milhas é uma alternativa interessante, dado o volume de valores gastos em cada trajeto. Dessa forma, a proposta do uso de milhagem está em consonância com as tendências indicadas por Belk (2014) e Martin (2016) sobre a economia compartilhada. Nela, o usuário pode usar as milhas da aplicação, ou importadas de outros programas, para uso compartilhado de trajetos.

Tendo em vista que os cenários propostos são de situações baseadas em necessidades reais e regulares, como ida e volta do trabalho nos dias úteis e outra viagem mais longa uma vez por semana, a falta de alternativas viáveis impõe aos envolvidos reservar diariamente valores para esse fim. Nesse sentido, Chase (2015) sugere o uso do compartilhamento em atividades regulares impactando diretamente em fatores econômicos, pois são economicamente mais viáveis a depender do estilo de vida e rotinas estabelecidas no dia a dia.

Apesar de um dos aplicativos utilizados nas simulações empregar pagamento on-line, esse é feito por cartão de crédito e atenderia parcialmente a proposta. Assim, as milhas seguiriam a tendência de pagamento on-line, dispensando o trâmite de pagamento em espécie, atendendo todo tipo de usuário.

Para determinar o gasto de combustível nos referidos trajetos das simulações, foram utilizados os valores médios de consumo para veículos compactos na cidade, na estrada e o valor médio do preço da gasolina. A Tabela 3 apresenta os valores obtidos.

Tabela 3 - Gasto de combustível com veículo particular

\begin{tabular}{lcccccc}
\hline $\begin{array}{c}\text { Trajeto por motorista } \\
\text { (Estado da Bahia) }\end{array}$ & $\begin{array}{c}\text { Percurso } \\
\text { p/ semana }\end{array}$ & $\begin{array}{c}\text { Km } \\
\text { semanal }\end{array}$ & $\begin{array}{c}\text { Valor } \\
\text { semanal (R\$) }\end{array}$ & $\begin{array}{c}\text { Percurso } \\
\text { p/ ano }\end{array}$ & $\begin{array}{c}\text { Km } \\
\text { anual }\end{array}$ & $\begin{array}{c}\text { Valor } \\
\text { anual (R\$) }\end{array}$ \\
\hline Salvador - Feira & 2 & 234,0 & 71,2 & 104 & 12.168 & $3.702,5$ \\
Lauro de Freitas - Ssa & 10 & 319,0 & 113,2 & 520 & 16.588 & $5.888,7$ \\
Salvador - Camaçari & 10 & 470,0 & 166,9 & 520 & 24.440 & $8.676,2$ \\
Paripe - C. das Árvores & 10 & 237,0 & 72,1 & 520 & 12.324 & $3.750,0$ \\
\hline
\end{tabular}

Fonte: Elaborado pelos autores (2019). 
Ao analisar a Tabela 3, percebe-se que a cultura do compartilhamento/carona pode se tornar fonte de estímulo ao revezamento do veículo, uma vez que os custos com ele seriam diluídos. Os gastos em dinheiro com combustível seriam revertidos em milhas para que o motorista as usasse como passageiro e, à medida que percebesse a queda desses gastos, deixasse de se deslocar com seu próprio carro e passasse a ser passageiro.

A Figura 1 demonstra uma situação baseada na Simulação 1, onde o trajeto médio pode gerar várias viagens mais curtas e, consequentemente, mais milhas em uma só viajem.

Figura 1 - Possibilidades de viagens em média distância no Estado da Bahia

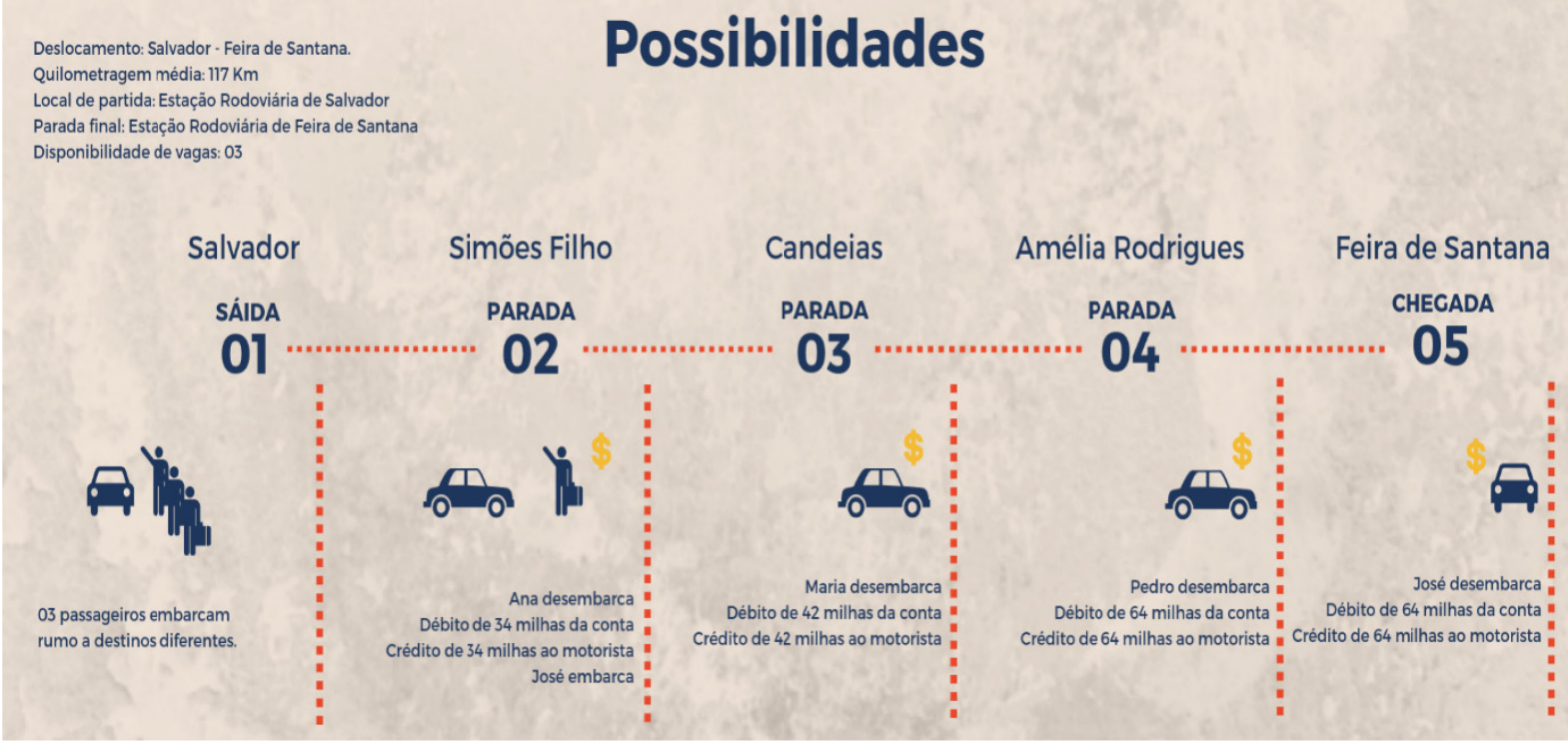

Fonte: Elaborado pelos autores (2019).

Um possível desdobramento baseado no cenário de uma viagem entre Salvador-Feira de Santana (Simulação 1) pode gerar quatro viagens e movimentação de milhas. A cada desembarque e confirmação no sistema, o processamento é feito pela transferência de milhagem para a conta do condutor. Nesse exemplo, de trajeto total de $117 \mathrm{~km}$, o condutor publicou a parada em pontos específicos possibilitando as caronas em trajetos mais curtos dentro do roteiro principal transferindo um total de 204 milhas no final do roteiro.

Ainda há perspectiva de estabelecer várias parcerias com empresas que fornecem diferenciados produtos. Parcerias com redes que já possuem sistemas de pontos abrem possibilidades para integração com o seu portfólio de produtos e, dessa forma, oportunizam a utilização das milhagens com outros serviços.

Assim, as milhas podem ser usadas para descontos em estabelecimentos, troca direta por produtos, ou transferência para outros programas de milhagem, como fazem as companhias aéreas. Tal cultura possibilita formas alternativas de atuação e é sustentada por Zalega (2018) que aponta o uso de tecnologias como forma de incentivo a essa prática de consumo, ou seja, fornecimento de uma forma diferenciada de pagamento on-line.

Nesse cenário, o motorista que, por motivo de força maior ou mesmo por opção, necessitar viajar sempre com o veículo próprio, excluindo a opção de ser passageiro, poderá utilizar as milhagens abatendo diretamente os custos com combustível através de abastecimento nas redes de postos conveniadas.

Supondo que as milhas geradas por caronas tenham utilização para além da mobilidade, por meio desses convênios/parcerias, haverá um custo benefício considerável levando os usuários a decidirem mais rapidamente sobre o compartilhamento dos assentos livres. A rede de incentivo poderá também atrair novos usuários à prática dessa forma de transporte.

Questões técnicas ainda estarão sob discussão, a depender do modelo de negócio que a empresa adotar para o funcionamento de milhagens, como por exemplo: Quem não possui veículo poderá gerar milhas, uma vez que o recebimento é feito pela ação de oferecer carona como condutor? A parceria poderá possibilitar 
transferência de milhagens externa e equivalência para a conta do usuário que não possui carro? Como será feita a valoração das milhas lançadas no sistema interno para os novos cadastros e, a partir daí, como serão geradas novas milhas? Um modelo pré-estabelecido poderá ser proposto aos possíveis parceiros que poderão analisar a viabilidade do estabelecimento da parceria e toda sistemática da compatibilidade entre os sistemas.

As simulações apresentadas mostraram diferentes cenários baseados em situações reais. A adoção de sistema de milhagem nos aplicativos de carona pode gerar praticidade com pagamentos e recebimentos online, sem a necessidade de portar o valor exclusivamente para o transporte, além de economia pela geração de valor devido à integração com outros programas.

Assim, o sistema de milhagem tornar-se consideravelmente atrativo tanto para usuários que possuem veículo quanto para os que não possuem, mas que podem realizar viagens por meios de pontos transferidos.

\section{CONCLUSÃO}

O presente estudo objetivou analisar a viabilidade técnica e processual para a implementação do sistema de milhagem em aplicativos de compartilhamento de carona. Os resultados evidenciaram que a proposta de fazer uma adequação tecnológica para implementação de sistema de milhagem em aplicativos de compartilhamento de carona é possível, pois nenhuma das aplicações analisadas utiliza sistema de fidelização como forma de pagamento.

Foi verificado que o fluxo de trabalho é similar em todos os aplicativos analisados, conforme demonstrado através do fluxograma, com particularidades apenas para eventuais transferências/uso de milhas. Essa adequação de implantação de uma moeda virtual similar ao sistema de pontos/milhagem objetiva tornar mais ágil o processo de compartilhamento do trajeto, por ser independente de moeda física (ou cartão) e, principalmente, ser bidirecional.

O estudo também investigou o funcionamento dos sistemas de fidelização que utilizam pontos/milhagem como forma de manter mais proximidade dos clientes com empresas como companhias aéreas e de outros seguimentos do mercado. A fidelidade do consumidor pode ser mantida através de uma rede de parcerias com integração a sistemas que oferecem outros produtos e serviços.

Os resultados da comparação destacaram características de três aplicativos de carona compartilhada mais ranqueados nas lojas virtuais, tornando viáveis as adequações nos sistemas com objetivo de incentivar as caronas com pagamento por milhas entre os usuários e vice-versa.

As simulações mostraram diferentes cenários em que a adoção de sistema de milhagem nos aplicativos é viável por darem potencial incremento tanto na praticidade dos pagamentos e recebimentos online quanto na economia pela geração de valor com integração a outros programas. Podem assim, fazer com que aplicativos de carona sejam atrativos para usuários possuidores ou não de veículos.

Como os valores monetários praticados já são ajustados por faixas de distância, o presente estudo sugere que a conversão de milhagem seja anexada integralmente a esses valores. Então, é importante considerar que o cálculo de retribuição se baseie diretamente nos critérios das distâncias quando a aplicação utilizar unicamente o sistema de milhas.

Portanto, com o estudo de viabilidade da adequação tecnológica, esse trabalho pôde trazer contribuições para a área de desenvolvimento de soluções de mobilidade, bem como contribuições para o segmento de compartilhamento de caronas e, através das análises e simulações, demonstraram que a adoção de milhagem como forma de pagamento nestas plataformas é viável.

\section{REFERÊNCIAS}

ABEMF - ASSOCIAÇÃO BRASILEIRA DE EMPRESAS DO MERCADO DE FIDELIZAÇÃO. Mercado de fidelidade segue crescendo, e empresas faturam 3,25 bilhões de reais no primeiro semestre. [2018]. Disponível em: https://www.abemf.com.br/press-release-mercado-de-fidelidade-segue-crescendo--e-empresas-faturam-325-bilhoes-de-reais-no-primeiro-semestre. Acesso em: 10 abr. 2019. 
AVIANCA. Programa Amigo. [2012]. Disponível em: https://www.pontosamigo.com.br/. Acesso em: 10 jun. 2018.

AZUL LINHAS AÉREAS. Programa TudoAzul. [2018]. Disponível em: https://www.maxmilhas.com.br/vendermilhas/azul-tudoazul. Acesso em: 05 jun. 2018.

BALDACCI, R.; MANIEZZO, V; MINGOZZI, A. An exact method for the car pooling problem based on lagrangean column generation. Operational Research, v. 52, n. 3, p. 422-439, June 2004. Disponível em: https://pubsonline.informs.org/doi/abs/10.1287/opre.1030.0106. Acesso em: 20 ago. 2018.

BARROS, A. P. B. G. A mobilidade urbana sob a perspectiva do pedestre. In: TACO, Pastor Willy Gonzales; SOUSA, Adriana Modesto de; SILVA, Philippe Barbosa (org.). Acessibilidade e mobilidade urbana na perspectiva da equidade e inclusão social. 1. ed. Goiânia: Kelps. [2018]. Livro2. Disponível em: http://www.transportes.unb.br/index.php?option=com_phocadownload\&view=category\&id=25\&ltemid=61 1. Acesso em: 21 fev. 2019.

BELK, R. W. You are what you can access: Sharing and collaborative consumption online. Journal of Business Research, v. 67, n. 8, p. 1595-1600, Aug. 2014. Doi: 10.1016/j.jbusres.2013.10.001. Disponível em: https://www.researchgate.net/publication/262490610_You_are_what_you_can_access_Sharing_and_collab orative_consumption_online. Acesso em: 18 fev. 2019.

BLABLACAR. BlaBlaCar. [2019]. Disponível em: www.blablacar.com.br. Acesso em: 04 jan. 2019.

BRUCK, Bruno P.; INCERTI, Valerio; IORI, Manuel; VIGNOLI, Matteo. Minimizing co2 emissions on a practical daily carpooling problem. In: XLVII Simpósio Brasileiro de Pesquisa Operacional.(SBPO), 2015, Porto de Galinhas - PE. Anais do XLVII Simpósio Brasileiro de Pesquisa Operacional. Porto de Galinhas: UFPE, 2015. p. 4142-4153. Disponível em: http://www.din.uem.br/sbpo/sbpo2015/pdf/142899.pdf. Acesso em: 01 mar. 2019.

CHASE, R. Economia compartilhada: como as pessoas e as plataformas estão reinventando a economia colaborativa e reinventando o capitalismo. São Paulo: Saraiva, 2015.

FARAJALLAH, M.; HAMMOND, B.; PÉNARD, T. What drives pricing behavior in Peer-to-Peer market? Evidence from the carsharing platform BlaBlaCar. [2016]. Disponivel em:

https://afse2016.sciencesconf.org/94699/document. Acesso em: 20 fev. 2019.

FRENKEN, K. Political economies and environmental futures of the sharing economy. [2017]. Disponível em: http://www.geo.uu.nl/isu/pdf/isu1701.pdf. Acesso em: 05 mar. 2019.

FURUHATA, M. et al. Ridesharing: The state-of-art and future directions. Transport Research Part B, n. 57, Parte B, p. 28-46. Disponível em:

https://pdfs.semanticscholar.org/1687/fd8c64b57270bdba488e7661b16b4d5117ef.pdf. Acesso em: 30 jul. 2018.

GIL, A. C. Métodos e técnicas de pesquisa social. 6. ed. São Paulo: Atlas, 2008.

GOL. Programa de fidelidade S.A. [2018]. Disponível em: https://www.smiles.com.br/programa-smiles. Acesso em: 10 jul. 2018.

GOOGLE. Busca de aplicativos [2019]. Disponível em: https://play.google.com/store. Acesso em: 10 fev. 2019.

INSTITUTO NACIONAL DE METROLOGIA, QUALIDADE E TECNOLOGIA (INMETRO). Tabela de Consumo. [2018]. Disponível em: http://www.inmetro.gov.br/consumidor/pbe/veiculos_leves_2018.pdf. Acesso em: 02 jan. 2019. 
IPIRANGA. Programa de Fidelidade Ipiranga. [2019]. Disponível em:

https://www.kmdevantagens.com.br/wps/portal/Applications/MarketPlace/. Acesso em: 17 jan. 2019.

INSTITUTO DE POLÍTICAS DE TRANSPORTE \& DESENVOLVIMENTO (ITPD). 0 que é carsharing? Embaixada Britânica Brasília. [2015]. Disponível em http://itdpbrasil.org.br/wp-content/uploads/2015/04/FS-Car-SharingCompleto.pdf. Acesso em: 21 mar. 2019.

LAKATOS, E. M.; MARCONI, M. A. Fundamentos de metodologia científica. 5. ed. São Paulo: Atlas, 2003.

LATAM. Pontos Multiplus. [2018]. Disponivel em: https://www.pontosmultiplus.com.br/home.

Acesso em: 15 jun. 2018.

LIMA, L. I. A Percepção de valor dos programas de milhagens: Um estudo exploratório. RAD Revista Administração em Diálogo, v. 17, n. 2, p. 129-150, maio/ago 2015. Disponível em:

https://revistas.pucsp.br/rad/article/download/18320/17426. Acesso em: 12 fev. 2019.

MACHADO, L.; PICCININI, L. S. Os desafios para a efetividade da implementação dos planos de mobilidade urbana: uma revisão sistemática. Rev. Bras. Gest. Urbana [online]. v. 10, n. 1, p. 72-94. Disponível em: http://www.scielo.br/scielo.php?pid=S2175-33692018005001104\&script=sci_abstract\&tlng=pt. Acesso em: 20 jan. 2019.

MARTIN, C. J. The sharing economy: A pathway to sustainability or a nightmarish form of neoliberal capitalism? Ecological Economics, n. 121, p. 149-159, 2016. Disponível em:

https://is.muni.cz/el/1423/jaro2017/HEN445/um/67863091/67863283/Martin_2016_The_sharing_economy_ 1_1_.pdf. Acesso em: 22 jan. 2019.

ROCHA, M. Cenários prospectivos para a competitividade do varejo de veículos no Brasil em 2040. (Dissertação). [2018]. Disponível em: https://bibliotecadigital.fgv.br/dspace/bitstream/handle/10438/23981/TA_vers\%C3\%A30\%20para\%20posta gem.pdf. Acesso em: 20 jan. 2019.

$\mathrm{SCHOR}$, J. B. Does the sharing economy increase inequality within the eighty percent? Findings from a qualitative study of platform providers. Cambridge Journal of Regions Economy and Society, v. 10, n. 2, p. 263-279, jul. 2017. Disponível em: https://doi.org/10.1093/cjres/rsw047. Acesso em: 14 mar. 2019.

SILVA, I. M. D. et al. A Crise da mobilidade urbana no Brasil: em foco a cidade de Fortaleza e o Sistema Bicicletar. [2017]. Disponível em: http://www.joinpp.ufma.br/jornadas/joinpp2017/pdfs/eixo11/acrisedamobilidadeurbananobrasilemfocoaci dadedefortalezaeosistemabicicletar.pdf. Acesso em: 20 de jan. de 2019.

VARGAS, H. C. Mobilidade Urbana nas Grandes Cidades. URBS, São Paulo, n. 47, ano XII, p 7-11, jul-ago-set. [2008]. Disponível em: http://www.labcom.fau.usp.br/wp-content/uploads/2015/08/2008-VARGAS-HelianaComin.-imobilidade-urbana.-URBS-S\%C3\%A3o-.pdf . Acesso em: 27 jul. 2018.

VTPI. Vehicle Rental Services That Substitute for Private Vehicle Ownership. TDM Encyclopedia, Victoria Transport Policy Institute. [2018]. Disponível em: https://www.vtpi.org/tdm/tdm7.htm. Acesso em: 18 ago. 2018.

WANSINK, B. Using laddering to understand and leverage a brand's equity. Qualitative Market Research: An International Journal, v. 6, n. 2, p. 111-118, 2003. Disponível em: https://doi.org/10.1108/13522750310470118. Acesso em: 13 jan. 2019.

WINSHIP, T. Airline Frequent Flyer Miles, 30 Years Later. The Washington Post, Washington, 25 May. [2011]. Disponível em: https://abcnews.go.com/Travel/airline-frequent-flyer-miles-30-years/story?id=13616082. Acesso em: 15 abr. 2019. 
ZALEGA, T. Collaborative consumption in consumer behavior of Polish young people. Journal of Economics \& Management, v. 33, p. 136-163, 2018.Disponível em:

http://cejsh.icm.edu.pl/cejsh/element/bwmeta1.element.cejsh-6838a2df-8f6a-4cd8-a4fc-940cded75d2b. Acesso em: 14 jan. 2019. 